\title{
Effective strategy of rescue treatment for acute pump thrombosis after left ventricular assist device implantation in patients with high risk of bleeding complications
}

\author{
Karol Wierzbicki, Izabela Górkiewicz-Kot, Anna Kędziora, Maciej Stąpór, Dorota Sobczyk, \\ Hubert Hymczak, Irena Milaniak, Michał Kaleta, Jacek Piątek, Bogusław Kapelak \\ Department of Cardiovascular Surgery and Transplantology, John Paul II Hospital, Jagiellonian University Medical College, Krakow, Poland
}

\section{INTRODUCTION}

Current indications for left ventricular assist device (LVAD) implantation include either chronic or acute heart failure (HF) in patients who cannot be stabilised with medical therapy and in whom the maintenance of sufficient end-organ perfusion is impossible. Based on international data, LVADs are now being used for months to years in patients who either face a long-term wait on the transplant list or who are not eligible for transplantation as a destination therapy [1]. Furthermore, by 2015, device implantation strategy has become a destination therapy in nearly $50 \%$ of implants [2].

Nevertheless, several challenges remain to be overcome before LVADs will be considered as the therapy of choice for all patients with advanced HF, because one-year survival free of any major adverse events remains at only 30\% [3, 4]. Although thrombotic events are not the most frequent complication, they can contribute significantly to patient mortality [5-7].

Suspected pump thrombosis (PT) is an event in which clinical or mechanical circulatory support device parameters suggest thrombus in the blood contacting components of the pump, cannulae, or grafts. Signs and symptoms should include at least two of the three following criteria: haemolysis, worsening HF, and abnormal pump parameters (elevated pump powers $>10 \mathrm{~W}$ or $2 \mathrm{~W}$ higher than baseline) [8].

Available methods of treatment involve one or more of the following interventions: treatment with intravenous anticoagulation (e.g. unfractionated heparin [UFH]), intravenous thrombolytics (e.g. tissue plasminogen activator [tPA]), or intravenous antiplatelet therapy (e.g. eptifibatide, tirofiban); pump replacement; pump explantation or urgent transplantation (United Network for Organ Sharing [UNOS] status 1A) [8].
Our Institution has experience with over 30 implants since October 2015 with both Heartmate III (Thoratec Corporation, Pleasanton, CA, USA) and HeartWare (Medtronic, Framingham, MA, USA) LVADs. In the study we present an innovative algorithm of rescue treatment for acute PT in patients with high risk of bleeding complications.

\section{METHODS}

The study is a retrospective analysis of medical records of three consecutive patients who underwent LVAD implantation in the Department of Cardiovascular Surgery and Transplantology, John Paul II Hospital, Krakow (Table 1). Following the implantation protocol, in all of the cases antithrombotic management within early postoperative days was obtained with intravenously administered UFH guided by activated partial thromboplastin time (up to $50 \mathrm{~s}$ within the first $48 \mathrm{~h}$ and $75 \mathrm{~s}$ in later postoperative days). After chest tube removal, warfarin was introduced with a target international normalised ratio (INR) of 3.0 to 3.5. On postoperative day 1 lavage function was enabled, following the manufacturer's recommendation, to diminish the risk of a potential thrombotic event.

\section{RESULTS AND DISCUSSION}

All patients received IV UFH bolus as soon as the PT diagnosis was established; however, no response to the treatment was observed. On the contrary, constant increase in LVAD power consumption was noted. All patients were considered to be at high risk of bleeding complications, with contraindications to standard thrombolytic approach. Moreover, our Institution does not have experience with emergent pump exchange. Facing the need for a rescue strategy, we elaborated an in-

\section{Address for correspondence:}

Anna Kędziora, MD, Department of Cardiovascular Surgery and Transplantology, John Paul II Hospital, ul. Prądnicka 80, 31-202 Kraków, Poland e-mail: anna.kedziora.mail@gmail.com

Received: 23.04.2018 Accepted: 23.05.2018

Kardiologia Polska Copyright (c) Polish Cardiac Society 2018 
Table 1. Patients' characteristics

\begin{tabular}{|c|c|c|c|}
\hline Variable & Patient P.M. & Patient G.P. & Patient K.M. \\
\hline Age [years] & 45 & 51 & 54 \\
\hline Sex & Male & Male & Male \\
\hline CAD & Yes & Yes & No \\
\hline Atrial fibrillation & Persistent & Paroxysmal & Paroxysmal \\
\hline ICD & Yes & Yes & Yes \\
\hline Cardiomyopathy & Dilated & Dilated & Dilated \\
\hline LVAD & HVAD & HVAD & HVAD \\
\hline Time to PT [months] & 4.5 & 13 & 20 \\
\hline Antithrombotic treatment on admission & Warfarin* & LMWH & LMWH \\
\hline Antiplatelet treatment on admission & ASA & ASA & ASA \\
\hline Primary reason for not taking VKA & - & $\begin{array}{c}\text { Severe GI bleeding, unstable INR } \\
\text { due to alcohol abuse }\end{array}$ & $\begin{array}{l}\text { Severe Gl } \\
\text { bleeding }\end{array}$ \\
\hline Time from onset of LMWH treatment to PT [months] & $-* *$ & 6 & 10.5 \\
\hline LVAD power consumption at the onset of IV tPA treatment [W] & 21 & 14 & $6: 61$ \\
\hline Maximum observed LDH level before onset of IV tPA treatment [U/L] & 11,592 & 9654 & 1753 \\
\hline
\end{tabular}

*Patient received antibiotics (rifampicin orally) due to a drive-line infection, bridged with LMWH but continued taking warfarin against prescribed treatment

**According to the patient warfarin was taken instead of LMWH for few days, probably 5

ASA — acetylsalicylic acid; CAD — coronary artery disease; GI — gastrointestinal; HVAD — HeartWare ventricular assist device; ICD — implantable cardioverter-defibrillator; INR — international normalised ratio; LDH — lactate dehydrogenase; LMWH — low-molecular-weight heparin;

LVAD — left ventricular assist device; PT — pump thrombosis; tPA — tissue plasminogen activator; VKA — vitamin K antagonists

novative algorithm of thrombolytic treatment guided by the LVAD power consumption and flow curves.

The UFH drip was discontinued and instant thrombolytic treatment was started. Thrombolysis was achieved with intravenous recombinant tPA, Actylise ${ }^{\circledR}$ (Boehringer Ingelheim, Ingelheim am Rhein, Germany) drip (50 mg/50 mL; starting flow $30 \mathrm{~mL} / \mathrm{h}$ ), which resulted in quick but stepwise drop in LVAD power consumption. The therapy was maintained until initial LVAD parameters were achieved, which was dynamically observed and analysed on the power consumption and flow curves. The drip flow was reduced gradually every 10 to 15 min, until complete withdrawal.

In two patients PT reoccurred within the same hospitalisation, and thrombolytic treatment was implemented successfully once and twice again following the same protocol (patients G.P. and P.M., respectively).

Currently, within a median follow-up of nine months since the thrombotic event (P.M. - 14 months, G.P. - nine months, K.M. - four months) all patients remain well, presenting New York Heart Association class I. After the PT event psychological consultation and further education were applied, and warfarin was implemented again as the anticoagulation therapy of choice, with good compliance. Patients are routinely monitored, and regular control of log-files and lactate dehydrogenase levels confirms proper LVAD functioning with no thrombotic events.
Despite steady improvement in survival since the implementation of the new-era continuous-flow pumps, the prevalence of PT with the HeartMate II and HeartWare LVADs is reported with a rate of 0.08 per patient/year [7, 9]. Although the aetiology and contribution of platelet- and thrombin-dependent pathways for thrombus formation in LVAD patients remain unclear [6], in the presented analysis all patients experienced a thrombotic event due to unsatisfactory outcomes of antithrombotic management. In two cases (G.P., K.M.), warfarin was discontinued and patients were bridged with therapeutic dose of subcutaneous low-molecular-weight heparin ( $\mathrm{LMWH}$ ) due to alcohol abuse undiagnosed prior to implantation. In both individuals with pathological INR reaching up to 11.0, severe and recurrent haemoglobin drops due to gastrointestinal bleedings were observed during warfarin administration. The third patient (P.M.) received antibiotics (rifampicin orally) due to a drive-line infection. The patient was bridged with $\mathrm{LMWH}$ due to a potential drug interaction; however, he continued taking warfarin orally despite prescribed treatment for about five days and did not take $\mathrm{LMWH}$.

The optimal strategy of treatment for various groups of patients experiencing PT remains unresolved. Based on the literature, strong conclusions should be drawn with caution, because the data are limited mostly to case reports, case series, or small, single-institution cohorts with a great variety 
of treatment strategies, drug choices, and delivery methods [5, 6, 9-11].

This proposed innovative algorithm of thrombolytic treatment guided by the power consumption and flow curves was elaborated while facing dramatic LVAD dysfunction and emergent need of rescue strategy in patients with high risk of bleeding complications. tPA was chosen as the safest available thrombolytic agent [12] and due to the algorithm, it was administered in the smallest effective dose.

The use of the log-system to predict the success of tPA treatment was first described in 2015 [10, 13]. Nevertheless, our report is the first to describe the usefulness of the real-time power and flow characteristic analysis to guide the thrombolytic therapy in patients with PT, which allows patient-tailored dosing because it is based on constant monitoring of effectiveness.

\section{Conflict of interest: none declared}

\section{References}

1. Ponikowski P, Voors AA, Anker SD, et al. 2016 ESC Guidelines for the diagnosis and treatment of acute and chronic heart failure: The Task Force for the diagnosis and treatment of acute and chronic heart failure of the European Society of Cardiology (ESC) Developed with the special contribution of the Heart Failure Association (HFA) of the ESC. Eur Heart J. 2016; 37(27): 2129-2200, doi: 10.1093/eurheartj/ehw128, indexed in Pubmed: 27206819.

2. Kirklin JK, Pagani FD, Kormos RL, et al. Eighth annual INTERMACS report: Special focus on framing the impact of adverse events. J Heart Lung Transplant. 2017; 36(10): 1080-1086, doi: 10.1016/j.healun.2017.07.005, indexed in Pubmed: 28942782.

3. Pinney SP, Anyanwu AC, Lala A, et al. Left ventricular assist devices for lifelong support. J Am Coll Cardiol. 2017; 69(23): 2845-2861, doi: 10.1016/j.jacc.2017.04.031, indexed in Pubmed: 28595702.

4. Kirklin JK, Naftel DC, Pagani FD, et al. Seventh INTERMACS annual report: 15,000 patients and counting. J Heart
Lung Transplant. 2015; 34(12): 1495-1504, doi: 10.1016/j. healun.2015.10.003, indexed in Pubmed: 26520247.

5. Kirklin JK, Naftel DC, Kormos RL, et al. Interagency Registry for Mechanically Assisted Circulatory Support (INTERMACS) analysis of pump thrombosis in the HeartMate II left ventricular assist device. J Heart Lung Transplant. 2014; 33(1): 12-22, doi: 10.1016/j. healun.2013.11.001, indexed in Pubmed: 24418730.

6. Shah P, Tantry US, Bliden KP, et al. Bleeding and thrombosis associated with ventricular assist device therapy. J Heart Lung Transplant. 2017; 36(11): 1164-1173, doi: 10.1016/j. healun.2017.05.008, indexed in Pubmed: 28579115.

7. Starling RC, Moazami N, Silvestry SC, et al. Unexpected abrupt increase in left ventricular assist device thrombosis. NEngl J Med. 2014; 370(1): 33-40, doi: 10.1056/NEJMoa1313385, indexed in Pubmed: 24283197.

8. Maltais S, Kilic A, Nathan S, et al. PREVENT Study Investigators. PREVENtion of HeartMate II Pump Thrombosis Through Clinical Management: The PREVENT multi-center study. J Heart Lung Transplant. 2017; 36(1): 1-12, doi: 10.1016/j. healun.2016.10.001, indexed in Pubmed: 27865732.

9. Mehra MR, Stewart GC, Uber PA. The vexing problem of thrombosis in long-term mechanical circulatory support. J Heart Lung Transplant. 2014; 33(1): 1-11, doi: 10.1016/j.healun.2013.12.002, indexed in Pubmed: 24418729.

10. Najjar SS, Slaughter MS, Pagani FD, et al. An analysis of pump thrombus events in patients in the HeartWare ADVANCE bridge to transplant and continued access protocol trial. J Heart Lung Transplant. 2014; 33(1): 23-34, doi: 10.1016/j. healun.2013.12.001, indexed in Pubmed: 24418731.

11. Tchantchaleishvili V, Luc JG, Phan K, et al. Management and Outcomes of LVAD Thrombosis: A Systematic Review and Meta-Analysis. J Heart Lung Transplantation. 2017; 36(4): S109-S110, doi: 10.1016/j.healun.2017.01.281.

12. Dang G, Epperla N, Muppidi V, et al. Medical management of pump-related thrombosis in patients with continuous-flow left ventricular assist devices: a systematic review and meta-analysis. ASAIOJ.2017;63(4):373-385, doi:10.1097/MAT.0000000000000497, indexed in Pubmed: 27984314.

13. Jorde UP, Aaronson KD, Najjar SS, et al. Identification and Management of Pump Thrombus in the HeartWare Left Ventricular Assist Device System: A Novel Approach Using Log File Analysis. JACC Heart Fail. 2015; 3(11): 849-856, doi: 10.1016/j. jchf.2015.06.015, indexed in Pubmed: 26454842.

Cite this article as: Wierzbicki K, Górkiewicz-Kot I, Kędziora A, et al. Effective strategy of rescue treatment for acute pump thrombosis after left ventricular assist device implantation in patients with high risk of bleeding complications. Kardiol Pol. 2018; 76(7): 1110-1112, doi: 10.5603/KP.2018.0135. 